\title{
A FEIRA DOS IMPORTADOS NO DISTRITO FEDERAL E O CIRCUITO INFERIOR DA ECONOMIA URBANA
}

\author{
Wellington Clay Porcino Silva ${ }^{1}$
}

\begin{abstract}
Resumo
A partir das materialidades geográficas da feira dos importados de Brasília, seus fixos e fluxos no território, serão analisadas como as características apontadas por Milton Santos para o Circuito Inferior da Economia Urbana são encontradas, total ou parcialmente, no funcionamento da chamada Feirinha do Paraguai, bem como seus desdobramentos territoriais. Assim, a metodologia trafega pela dinâmica fluida entre teoria e campo, caracterizada pelo trabalho geográfico de base no qual há constante diálogo entre os espaços sociais e seus determinantes territoriais. Na análise entre os territórios normados a partir da existência da feira, verificar-se o movimento fomentado pelo Estado para ordenamento das atividades do circuito inferior (burocratização), verificando-se as condições de êxito e os pontos limitantes.
\end{abstract}

Palavras-Chave: Milton Santos, Circuitos da Economia Urbana, Comércio Popular

\section{IMPORTED PRODUCTS FAIR IN DISTRICT FEDERAL AND LOWER CIRCUIT OF URBAN ECONOMY}

\begin{abstract}
From the geographic objects of "Feira dos Importados", its fixed and flows in the territory, will be analyzed how the characteristics pointed out by Milton Santos for the Lower Circuit of the Urban Economy are found, totally or partially, in the functioning of the so-called "Feirinha do Paraguai", as well as its territorial developments. Thus, the methodology travels through the fluid dynamics between theory and field, characterized by the basic geographic work in which there is constant dialogue between social spaces and their territorial determinants. In the analysis between the normed territories from the existence of the fair, the movement promoted by the State to order the activities of the lower circuit (bureaucratization) was verified, verifying the conditions of success and the limiting points.
\end{abstract}

Keyword: Milton Santos, Urban Economy Circuits, Popular Trade

\section{LA FOIRE DES IMPORTÉS ET LE CIRCUIT INFÉRIEUR D'ÉCONOMIE URBAINE}

\section{Résumé}

À partir des objets géographiques de la "Feira dos Importados", de son fixe et de son flux sur le territoire, nous analyserons comment les caractéristiques soulignées par Milton Santos pour le circuit inférieur de l'économie urbaine se retrouvent, totalement ou partiellement, dans le fonctionnement de la société - appelé "Feirinha do Paraguai", ainsi que ses développements territoriaux. Ainsi, la méthodologie parcourt la dynamique fluide entre la théorie et le domaine,

\footnotetext{
${ }^{1}$ Doutorando em Geografia pela Universidade Federal do Rio Grande do Norte. Mestre em Ciência e Sistemas de Informações Geográficas pela Universidade Nova de Lisboa e em Ciências Militares pela Escola de Aperfeiçoamento de Oficiais do Exército.

E-mail: wellington.wcps@gmail.com
} 
caractérisée par le travail géographique de base dans lequel il existe un dialogue constant entre les espaces sociaux et leurs déterminants territoriaux. Dans l'analyse entre les territoires normés depuis l'existence de la foire, le mouvement promu par l'État pour ordonner les activités du circuit inférieur (bureaucratisation) a été vérifié, en vérifiant les conditions de réussite et les points limites.

Mot clé: Milton Santos, Circuits d'économie urbaine, Commerce populaire

\section{INTRODUÇÃO}

Pensar o espaço geográfico em tempos contemporâneos demanda a análise territorial de diferentes fenômenos sociais ligados à dinâmica das cidades, discutindo aquilo que Milton Santos caracteriza como Circuito Inferior da Economia Urbana. Nesta perspectiva, os diferentes fenômenos urbanos são vistos por meio da rede de relações entre os objetos e ações que os compõem (SANTOS, 1979), conforme se pode obsevar a partir das dinâmicas territoriais ligadas as feiras e comércios que marcam os espaços das cidades.

Seguindo esta perspectiva geográfica, o presente trabalho tem como objetivo analisar o funcionamento da Feira dos Importados, localizada no Distrito Federal, também conhecida como Feirinha do Paraguai, buscando identificar as características do Circuito Inferior da Economia Urbana, conforme apontado por Milton Santos em sua obra "O Espaço Dividido" (SANTOS, 1979).

No intento de compreender a dinâmica territorial da feira enquanto objeto de um circuito econômico, essa dissertativa se encontra dividida em três partes: a primeira realiza uma descrição da Feira dos Importados, marcando a presença de seus objeto e práticas espaciais ao apontar origem, localização, número de boxes em funcionamento, área utilizada. A segunda caracteriza o Circuito Inferior da Economia Urbana, com base em pesquisa bibliográfica que serve de base teórica à terceira etapa da discussão de dados, na qual, a partir de uma pesquisa realizada através de entrevistas feitas com trabalhadores, buscar-se-á identificá-las no funcionamento da Feira dos Importados.

A partir das materialidades geográficas da feira, seus fixos e fluxos no território, serão analisadas como as características apontadas por Milton Santos para o Circuito Inferior da Economia Urbana são encontradas, total ou parcialmente, no funcionamento da chamada 
Feirinha do Paraguai, bem como seus desdobramentos territoriais. Assim, a metodologia trafega pela dinâmica fluida entre teoria e campo, caracterizada pelo trabalho geográfico de base no qual há constante diálogo entre os espaços sociais e seus determinantes territoriais. Na análise entre os territórios normados a partir da existência da feira, verificar-se o movimento fomentado pelo Estado para ordenamento das atividades do circuito inferior (burocratização), verificandose as condições de êxito e os pontos limitantes. Nesse ponto analisar-se-ão, principalmente, as questões relacionadas ao cumprimento das obrigações tributárias, trabalhistas e, principalmente, dada a sua relevância, no tocante à legalidade da atividade, com possíveis reflexos na regulação do espaço e suas consequências nas esferas administrativa e penal.

\section{A FEIRA DOS IMPORTADOS E SUA INSERÇÃO GEOGRÁFICA}

A Feira dos importados compõe uma importante marca urbana na paisagem de Brasília. Por isso, faz-se necessário uma boa compreensão técnica de sua estrutura para que se possa discutir porteriormente sua dinâmica territorial. Atualmente, localizada no Setor de Indústria e Abastecimento (SIA) - Sul, Trecho 7, Lotes 5 a 180, Setor de Comércio Especial, tem sua origem na feira popular, denominada então de Feirinha do Paraguai, que se formou espontaneamente na região central de Brasília/DF, próximo ao Estádio Mané Garrincha, por volta de meados dos anos $1990^{2}$. Todavia, foi no ano de 1997 que a então denominada Feirinha do Paraguai foi transferida da área central para uma região fora do Plano Piloto e que pertencia à CEASA/DF, onde se localiza até hoje.

A estes se somaram outros feirantes oriundos de diversas regiões do Distrito Federal (CONIG, Guará), para formar a hoje denominada Feira dos Importados. Ela ocupa uma área de aproximadamente $70.000 \mathrm{~m}^{2}$, ao longo do qual estão distribuídos 1990 (mil novecentos e noventa) boxes e 96 (noventa e seis) quiosques, ocupados por 1758 (mil setecentos e cinquenta e oito) permissionários.

É interessante ressaltar esta divisão entre quiosques e boxes, dois fixos geograficos que materializam a presença da feira no espaço brasiliense. Os quiosques ocupam as áreas externas do quadrilátero que forma a feira (os lados do quadrado) e caracterizam-se por abrigarem estabelecimentos comerciais de envergadura maior que os boxes, com um número superior de funcionários, embora sem se distanciarem das características do circuito inferior da economia

\footnotetext{
${ }^{2}$ Informação on-line, conferir em: http://www.feiradosimportados.net.br/historico
} 
urbana. Já os boxes são as unidades internas, divididas em corredores, ocupando a maior parte do espaço físico da feira. São estabelecimento de porte muito pequeno, contando com pouquíssimos funcionários, como se apresentará no tópico próprio, já referenciado no parágrafo acima.

A diferença entre o número de espaços disponíveis e o total de permissionários é resultante da possibilidade de um mesmo permissionário utilizar mais de uma unidade adjacente, de modo a ampliarem seus negócios. Contudo, a pequena diferença de apenas 358, em um universo de 2.086, já demonstra que a maioria esmagadora de permissionários se utiliza tão somente de um único boxe, demonstrando a predominância dos comércios de tamanho reduzido.

Nessa vasta área, são negociados os mais diversos tipos de produtos, incluindo produtos alimentares e roupas. Porém, a grande maioria dos quiosques se dedica à venda de produtos eletroeletrônicos e de informática, apresentando preços inferiores aos praticados nas grandes lojas do Distrito Federal. Vizualiza-se a seguir imagem de visão panorâmica da área ocupada pela feira dos importados:

Figura 1: Visão da Feira dos Importados de Brasília/DF

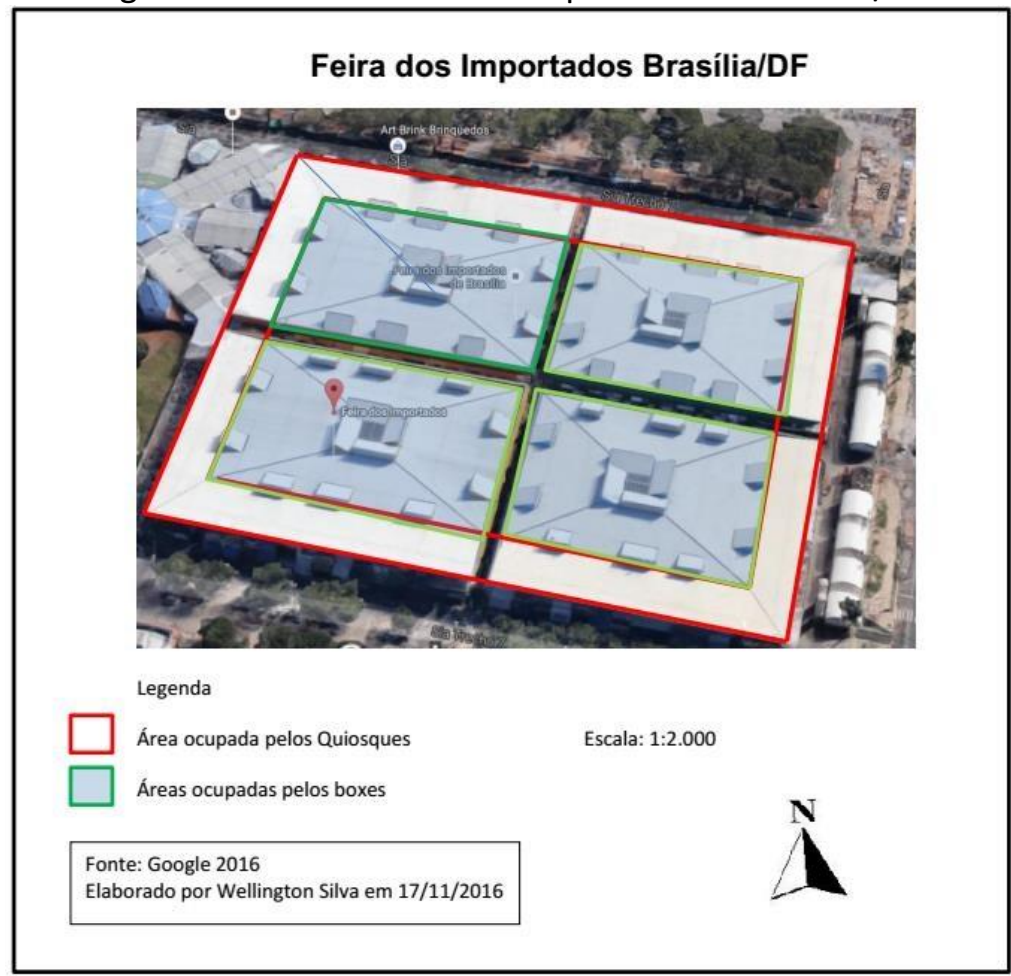

Fonte: Sítio do Google Maps ,2016 
Esta presença espacial da feira se torna ainda mais relevante quando se avança à compreensão espacial mais ampla de seu impacto no território brasiliense. Isto pode ser observado no mapa a seguir que permite verificar a localização da Feira dos Importados em relação aos principais locais de moradia da Classes A e B no Distrito Federal: as Asas Sul e Norte, Lagos Sul e Norte e o Setor Sudoeste, bem como dos grandes eixos rodoviários, lembrando-se que a mencionada Feira encontra-se no Setor de Indústria e Abastecimento, conhecido como SIA.

Figura 2: Localização do SIA em relação às demais áreas de moradia do DF

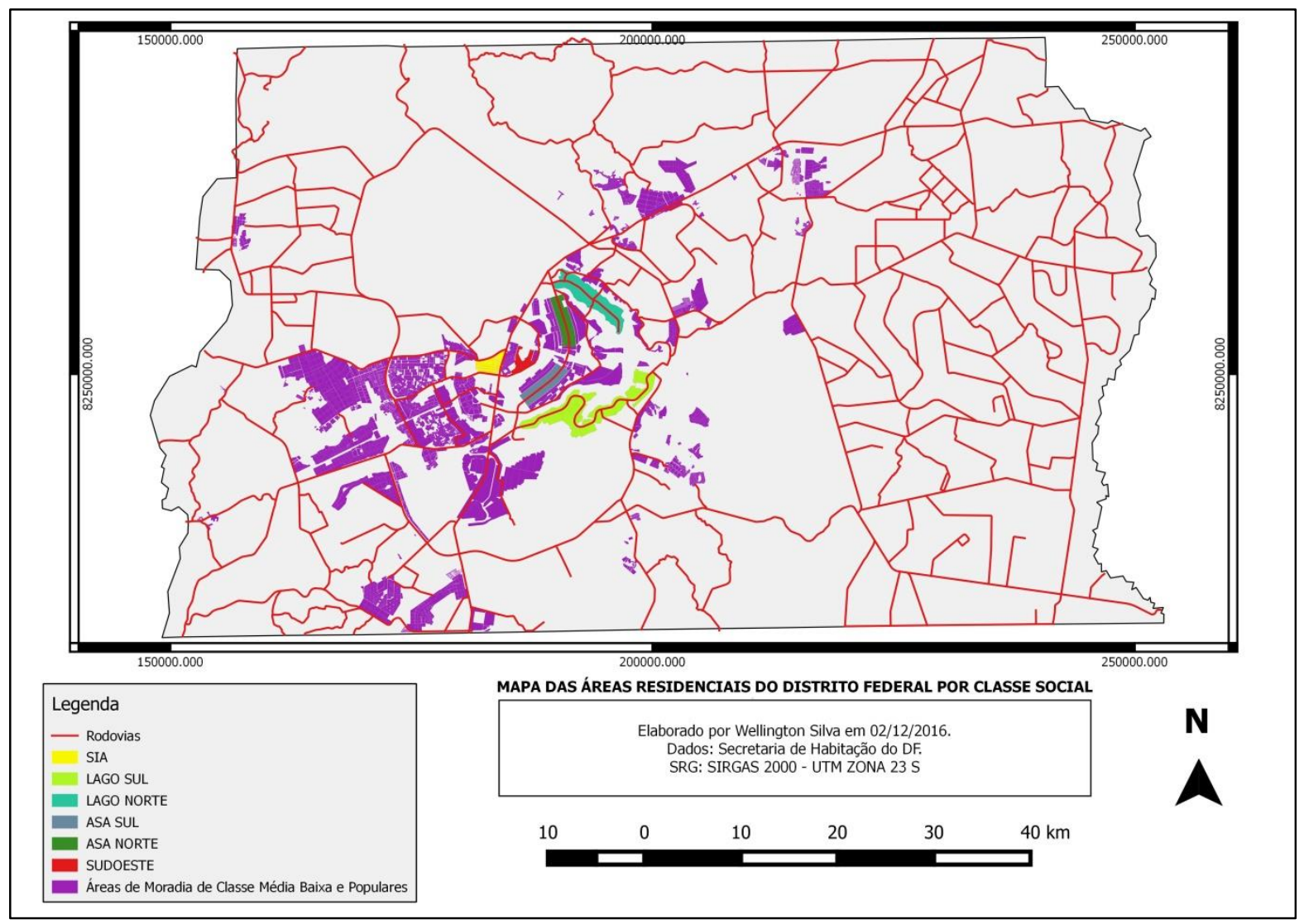

Fonte: Secretária de Habitação do DF, 2016

As principais materialidades da feira, bem como seu fluxo comercial, podem ser observadas nas imagens a seguir. A partir delas, é possível pensar sobre seu papel social enquanto espaço de articulação entre diferentes agentes das classes médias e populares, bem como o impacto na economia local. Nas fotografias observa-se os quiosques e o corredor central da feira, com os boxes, como forma de permitir uma visualização da estrutura de forma mais próxima. 


\section{Figura 3: Área externa com Quiosques}

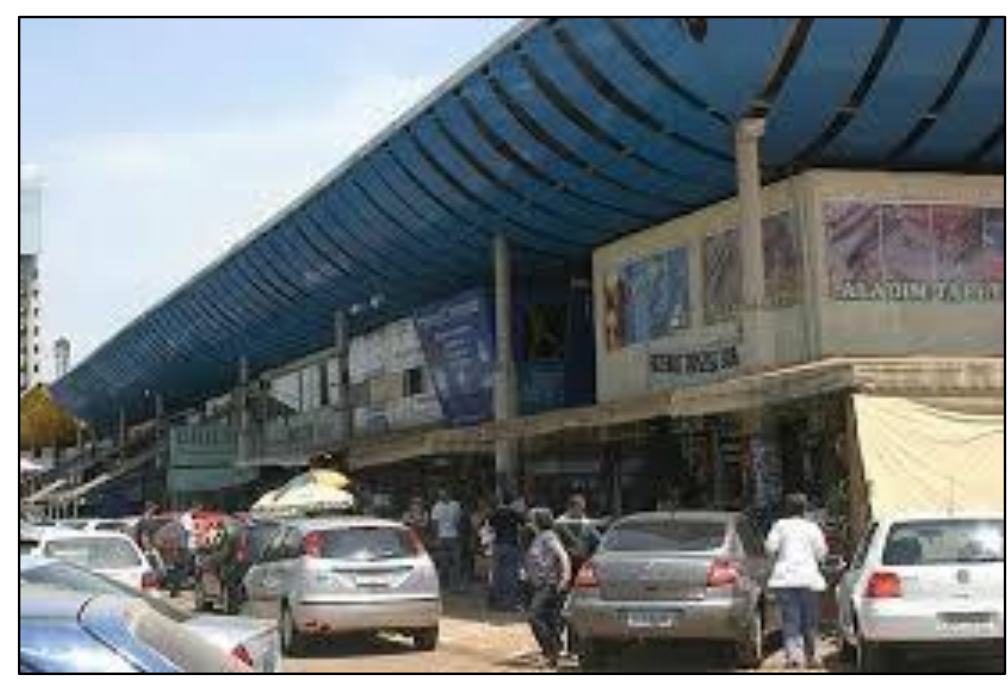

Fonte: Sítio Eletrônico da Feira dos Importados, 2016

Figura 4: Corredor Central ladeado por boxes

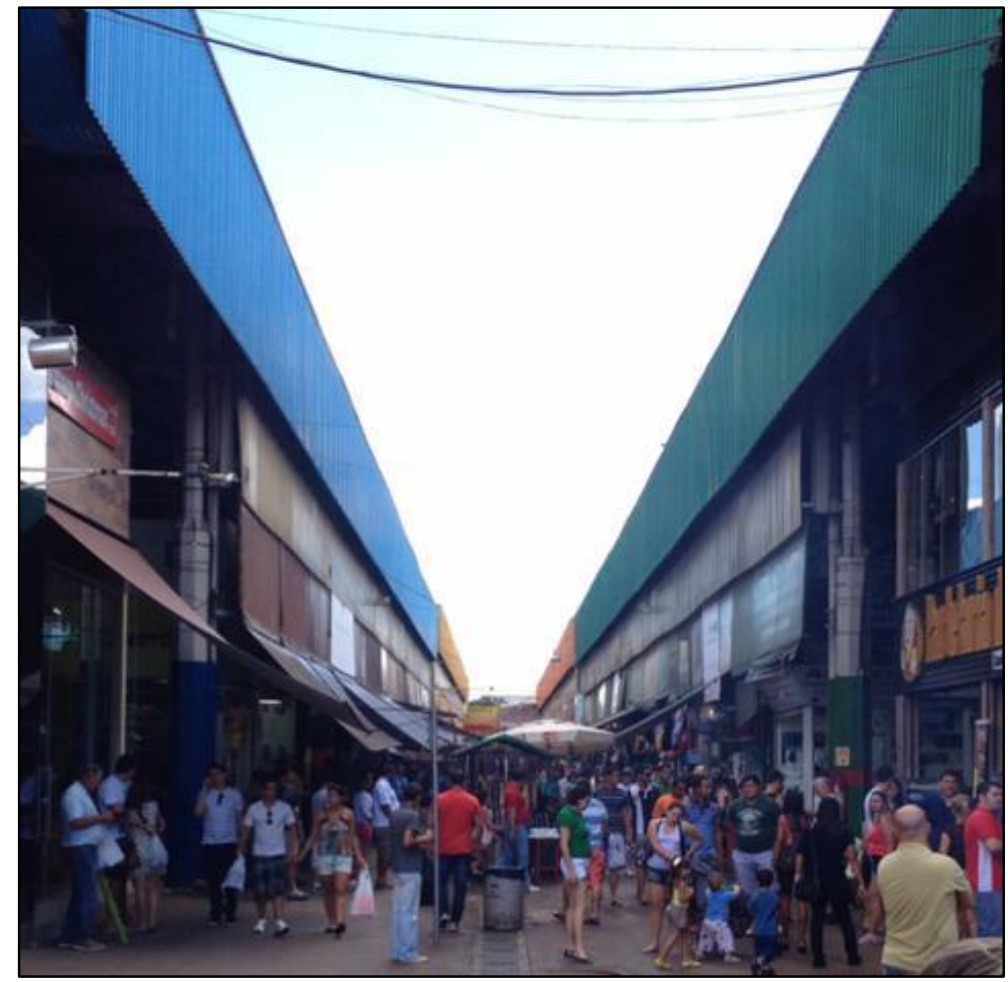

Fonte: Sítio Eletrônico da Feira dos Importados, 2016

Algumas questões geográficas que podem ser analisadas a partir das materialidades que compõem a feira, bem como de seus sistemas de objetos e ações territoriais, tratam de: miscigenação entre comércio formal e informal; intenso potencial de dispersão no território 
distrital; diversidades e fixos e fluxos que demandam a análise dos circuitos inferiores da economia gerada neste espaço.

\section{OS CIRCUITOS DA ECONOMIA URBANA: ELEMENTOS TEÓRICOS PARA LER A DINÂMICA DA FEIRA LIVRE}

A Teoria dos Circuitos da Economia Urbana foi proposta por Milton Santos em seu livro "O Espaço Dividido" numa primeira edição datada de 1979. Esta teoria baseia-se na necessidade de se buscar uma formulação de teoria econômica para explicar a realidade do mundo subdesenvolvido, juntamente com o desenvolvimento de uma teoria espacial capaz de justificar, coerentemente, a ocupação dos espaços no mundo considerado enquanto subdesenvolvido.

Santos (1979) apresenta que há três grandes períodos históricos de modernização que irão produzir um contexto de complexidade sobre os circuitos da economia, a saber: 1) do fim do século XV / início do século XVI até a revolução industrial, representado pela revolução comercial; 2) de meados do século XVIII até meados do século XX, caracterizado pelo desenvolvimento da revolução industrial (até 1870) e de seus suportes (após 1870); e 3) o período atual, marcado pela revolução tecnológica.

Frente ao contexto atual, a evolução tecnológica, comandada pela força dos grandes complexos industriais se impõe, em especial pela rápida evolução dos meios de difusão da informação. E, ao contrário dos demais momentos históricos, a informação e o consumo, aquela sempre a serviço desse, encontram-se difundidas também nos países periféricos, o que impacta de forma significativa a ocupação do espaço nessas regiões.

Explica-se a distribuição espacial, principalmente, através da difusão da informação e da difusão do consumo. A consciência de novos bens de consumo, graças a uma ampla difusão das informações, implica em um aumento na propensão geral ao consumo. É o chamado efeitodemonstração e tem como um de seus resultados a redução pela demanda por produtos locais ou suscetíveis de produção com pouca dependência externa, ocasionando um aumento da demanda sem um crescimento de renda compatível.

Segundo Linhares (2003, p. 6), sobre o efeito demonstração podemos dizer o que se segue: 


\begin{abstract}
O efeito demonstração diz respeito à visibilidade que os objetos modernos ganham principalmente em função do amplo alcance das tecnologias de comunicação e informação. Contudo, grande parcela da população não está apta a ter acesso das benesses do meio técnico científico, uma vez que seu poder aquisitivo de consumo se revela baixo e as autoridades públicas não assistem essa camada da população. [...]. Aumenta-se a propensão marginal ao consumo sem que haja como contrapartida um aumento da renda, o que traz no seu bojo um conflito ou uma contradição com a qual as classes sociais mais baixas têm que conviver.
\end{abstract}

Assim, essa drástica mudança nos mecanismos do consumo deformou a estrutura então existente no próprio consumo, o que acarretou o desenvolvimento de novas formas de produção e de comércio, com o nítido objetivo de atender as novas demandas criadas pelo meio técnicocientífico informacional nas camadas mais desfavorecidas.

Também como consequência dos avanços tecnológicos mais recentes, houve nos países subdesenvolvidos uma diminuição no total de empregos relacionados à indústria, pois essa se torna capital intensivo, e não mais de mão de obra intensiva.

Paralelamente, também há na agricultura redução da força de trabalho empregada. Tudo isso, leva-se ao êxodo rural e à urbanização terciária, com o mercado de trabalho nas cidades se deteriorando, com um contingente grande de pessoas sem rendas permanentes.

Cria-se desse modo, nas cidades, uma massa de pessoas com salários muito baixos ou ainda vivendo de atividades ocasionais ao lado daquelas poucas com renda muito elevada. Aparece, então, nessas áreas urbanas, uma divisão entre aqueles que com acesso permanente aos bens de consumo desejados e aqueles que, embora tenham as mesmas necessidades, não conseguem satisfazê-las, criando-se diferenças qualitativas e quantitativas no consumo. Essa é, então, a causa e efeito da existência dos dois circuitos urbanos de produção, distribuição e consumo de bens e serviços.

Tais circuitos são resultantes do processo atual de modernização, sendo que o circuito superior é seu resultado direto, criado a partir dos progressos tecnológicos e daqueles que dele se beneficiam.

O inferior, embora também seja resultado da nova modernização, é um resultado indireto. Possui foco nas pessoas à margem das inovações tecnológicas ou parcialmente inseridas. Tais circuitos se encontram presentes nas cidades dos países subdesenvolvidos, onde há lacunas consideráveis no processo formalização da economia e de sua distribuição no território (SANTOS, 1999). 
O tema dos dois circuitos da economia urbana passa a ser o paradigma da Geografia Urbana e do planejamento nos países subdesenvolvidos. Assim, um autor denomina esses circuitos de superior e inferior, já que é difícil enquadrar o primeiro como moderno, além de não se poder, com precisão datá-lo, e o segundo como tradicional, já que é fruto do processo de modernização. Assim, o que identifica cada um desses circuitos é sua forma de organização e comportamento. Outro ponto salutar dessa denominação é ressaltar a mútua dependência entre circuito inferior em relação ao superior.

Assim, de forma simplificada, o circuito superior seria formado pelas grandes estruturas econômicas bancos, comércios e indústria de exportação, pela indústria moderna, além dos serviços modernos, atacadistas e transportadores. $\mathrm{O}$ circuito inferior, por sua vez, é formado pelas formas de fabricação de capital "não intensivo", pelos serviços com limite de acesso aos recursos considerados modernos, fornecidos "a varejo" e pelo comércio não moderno e de pequena dimensão.

Há, no circuito superior, atividades que podem ser consideradas puras (indústria, comércio e serviços modernos), mistas (atacadistas e transportadores, pois possuem ligação com ambos os circuitos) e impuras. Nas palavras de Silveira $(2009,65)$ :

\begin{abstract}
Atividades bancárias e financeiras, comércios, indústrias e serviços modernos, frequentemente orientados para a exportação, constituem o circuito superior. Derivado dele, identificamos uma economia pobre, constituída por atividades de fabricação, comércio e serviços cujo grau de capitalização, tecnologia e organização é relativamente baixo. É o circuito inferior da economia urbana.
\end{abstract}

Porém a definição dos circuitos não se faz somente com seus elementos, mas do conjunto das atividades realizadas dentro de certo contexto e pelo setor da população que se liga a ele essencialmente pela atividade e pelo consumo. Ressalte-se, contudo, que tal definição não é rígida, já que as camadas da população podem consumir fora de seu circuito, ainda que de forma limitada, e a classe média tem seu consumo frequentemente dirigido tanto à classe abastada quanto à classe pobre.

A diferença fundamental entre o circuito superior e inferior é baseada na tecnologia e na organização. Enquanto o primeiro possui tecnologia de capital intensivo, o segundo caracteriza-se por atividades de "trabalho intensivo", com capitais reduzidos e podendo dispensar organização burocrática, tendo ainda, como relevante a criatividade, que se opõe a rigidez do circuito superior. 
Assim, o trabalho oferecido no circuito superior, como consequência de sua forma de organização, é basicamente assalariado. Já o circuito inferior, com sua remuneração normalmente eventual e baixa, baseada em acordos pessoais entre empregado e patrão, possuindo ainda grande relevância o trabalho familiar. No entanto, embora o número de empregados por unidade seja baixo, no total, ocupa um número considerável de pessoas, sendo um considerável gerador de ocupação para a camada pobre da população urbana.

$\mathrm{Na}$ formação de preços, o circuito superior se caracteriza por uma rigidez, em razão da necessidade de não se colocar em risco a empresa, enquanto no inferior é natural se "barganhar", negociar o preço. O primeiro tem como objetivo a acumulação de capitais indispensáveis à manutenção da atividade e sua evolução, enquanto no inferior se busca, basicamente, a subsistência.

A publicidade, responsável pela modificação dos gostos e pela deformação do perfil da demanda, é base, em grande parte, da atividade do circuito superior. Já, no circuito inferior, tal publicidade é desnecessária, já que nele há contato direto com a clientela. Além do que, não há espaço para gastos com publicidade, uma vez que a renda extra obtida é destinada à subsistência. Há uma diferenciação também em relação aos custos fixos, sendo que esses, relevantes no circuito superior, são quase inexistentes no circuito inferior. No caso do circuito superior não existe, ou é quase nula, a reutilização dos bens de consumo duráveis, ao passo que no inferior tal reutilização é uma de suas mais importantes características, como demonstram as oficinas de conserto de roupas e aparelhos.

Quanto ao auxílio do governo, enquanto o circuito superior usufrui de ajuda governamental, contando com subvenções e políticas de produção e consumo enquanto o circuito inferior não depende desta, ao contrário, muitas vezes suas atividades são alvo de perseguições. Para seu funcionamento, o circuito superior depende de uma produção de capital intensivo com o consumo, já que ligado ao poder de compra, seletivo, dependendo de gastos em publicidade para criar novas demandas, impondo-a. $\mathrm{O}$ inferior, em vez de basear-se na produção, depende totalmente do consumo, resultado da demanda, ainda que deformada pelo efeito-demonstração.

O circuito inferior é controlado, subordinado, dependente do circuito superior que tende a controlar a economia formal, diretamente ou através do Estado. Outra diferença 
relevante entre os circuitos superior e inferior é a integração, pois, enquanto as atividades realizadas pelo segundo integram-se localmente, no primeiro essas se integram a outras escalas nacionais e internacionais.

Percebe-se, ao analisar suas características, que embora haja diferenciação entre ambos os circuitos, há uma complementariedade entre esses, inexistindo, dessa forma, um dualismo entre ambos. O que encontramos são dois circuitos de mesma origem, mesmo conjunto de causas, interligados entre si.

\section{O Circuito Inferior da Economia Urbana}

Tendo em vista que o objeto do presente artigo é buscar identificar os elementos do circuito inferior da economia urbana no funcionamento da Feira dos Importados no Distrito Federal, bem como verificar o estabelecimento de sua territorialidade, ainda será buscado em Milton Santos (1979), recursos para discutir o circuito inferior da economia urbana e sua dinâmica.

A evolução da economia urbana, com uma grande população com baixo nível de vida, levou ao desenvolvimento de um circuito inferior. Tal circuito é composto de unidades de produção e comércio de dimensão reduzida e que trabalham com pequenas quantidades.

Nesse circuito há um grande número de empresas familiares e de autônomos, com pouco capital e utilizando-se de tecnologia obsoleta e equipamento de má qualidade (normalmente por falta de capital) e em um sistema de negócios arcaico, com organização deficiente, sem gastos com publicidade. Ocorre, ainda, uma substituição da poupança pelo endividamento.

Caracteriza-se, ainda, pela grande criatividade daqueles que o compõe, em um sistema em que nada se desperdiça, com reutilização de materiais anteriormente consumidos. O circuito inferior não se confunde com o setor "terciário", abrangendo uma realidade muito mais ampla, englobando atividades de serviço (como doméstica e transportes), atividades de transformação (artesanais ou formas pré-modernas de fabricação), servindo, ainda como abrigo para a população pobre, que raramente pode consumir e trabalhar no circuito superior.

O Circuito inferior se constitui no abrigo para a população urbana pobre e de pouca qualificação, oriunda ou não de movimentos migratórios. Há uma grande fragmentação das atividades, com um grande número de total de vagas. Embora o número gerado de vagas por estabelecimento seja muito reduzido, a grande quantidade destes, permite acolher número significativo de trabalhadores que não encontrariam amparo no circuito moderno. Possui, ainda, 
elevado índice de divisão de tarefas, sendo estas pulverizadas, de modo a acolher o maior número de pessoal possível (SANTOS, 1979).

O emprego no circuito inferior é de difícil definição, pois abarca diversas realidades, como o trabalho mal remunerado e o trabalho temporário ou instável. O ingresso no circuito inferior é, de modo geral, fácil, pois suas atividades são intensivas em trabalho, exigindo pouco capital. Em decorrência do baixo custo do investimento inicial, a abertura de pequenos negócios ocorre com demasiada facilidade e em breve intervalo entre planejamento e instalação.

Simplificando-se, pode-se reconhecer três tipos de atividades do ponto de vista de dificuldades de ingresso, a saber: 1) as que não exigem nem capital nem qualificação; 2) as que exigem tão somente algum capital e 3) as que exigem algum nível de qualificação e capital.

É através dos serviços que a massa da população urbana participa da acumulação, em razão da má distribuição de rendas. O Consumo de serviços pessoais é elemento importante do padrão de vida, o que gera grande número de vagas no circuito inferior.

O Comércio ocupa um número grande de pessoas, uma vez que é muito fácil iniciar uma loja, com pequena soma de dinheiro, podendo-se apelar para o crédito pessoal ou em mercadoria, não necessitando de experiência e, ainda, de modo fácil, pode-se evitar o pagamento de impostos.

Os lojistas de econominas em desenvolvimento caracterizam-se pela pequena dimensão de seus negócios. Isso ocorre em todas as atividades do circuito inferior, ou seja, ele é composto por pequenas indústrias, artesanatos e serviços, com capital e volume de negócios reduzidos, estoques pequenos e com número reduzido de pessoas, além de exigirem pouco espaço.

No circuito inferior, as atividades econômicas são pulverizadas, em especial o comércio, ou seja, são realizadas por um grande número de empresas de pequena dimensão. Outra característica importante é a densidade do comércio. Essa densidade e a distribuição estão calcadas nas possibilidades de deslocamento a pé dos clientes, já que esses compram no local, até mesmo em razão do custo do transporte.

As lojas são pequenas em razão do consumo pequeno e irregular, caracterizado como microvarejo. Ressalte-se que, quanto mais pobre a população menor é a dimensão dos comércios. Tais comércios têm, ainda, como característica, trabalhar com estoques muito reduzidos. A razão para tal fato pode ser explicada nas características do consumo do circuito 
inferior. Há um fracionamento das compras dos clientes, compra-se um pouco todo dia (ibidem).

Por seu lado, o comerciante se reabastece em pequenas quantidades diariamente, já que precisa ter um estoque diversificado, com pouco espaço de armazenamento, além de não possuir condições de armazenamento de gêneros perecíveis por longos períodos. Só se estoca o que pode vender ou estocar, renovando-se os estoques tanto mais rápido quanto for menor o capital investido.

Esses estabelecimentos ocupam em geral espaços pequenos, sendo inclusive comum que o local de trabalho seja a própria habitação, já que se constitui uma economia de tempo e dinheiro e porque, via de regra, esta é a única alternativa para o negócio (ibidem).

No nível inferior da pulverização do comércio, encontram-se os vendedores de rua. Eles possuem menor dependência da clientela, buscando-a. Esse tipo de comércio permite, ainda, escapar dos impostos. Existem dois tipos de vendedores de rua: os que têm seu local fixo na calçada e andam com mercadorias nas ruas do centro das cidades e aqueles que vão procurar clientes nos bairros.

Outra característica do circuito inferior é a relevância do trabalho familiar, já que permite o aumento da produção, sem que haja necessidade de maior mobilização de capital de giro. Tal circuito oferece à população pobre um grande número de empregos devido à multiplicidade de pequenas empresas, familiares ou individuais geralmente. Contudo, cada unidade de produção oferece um pequeno número de empregos.

Nos países subdesenvolvidos e desenvolvidos há uma proliferação dos intermediários, porém por razões diversas. Nos países centrais, busca-se, pela especialização, uma melhor produtividade e cria-se um mercado para as atividades de serviço.

Já nos países com economia em situação periférica, a existência de intermediários é uma condição, a base das possibilidades estruturais de funcionamento da economia, já que devido às desigualdades de renda, não haveria como funcionar sem ela. Quanto mais pobre o indivíduo, mais ele depende dos intermediários para se abastecer, e essa dependência é tanto maior quanto for o tamanho da cidade.

Com a urbanização, agrega-se à função do intermediário o papel de coletor de produtos alimentares, já que os comerciantes não têm condições de se abastecerem diretamente nos produtores, importadores e atacadistas (ibidem). 
Assim, o intermediário, seja atacadista ou proprietário de caminhão, serve como elo entre demanda e oferta que não coincidem no tempo, nem na qualidade ou quantidade. Isso lhe dá uma posição estratégica, porque é o único que dispõe de crédito bancário, e portanto de dinheiro líquido para efetuar compras diretamente ou de outros intermediários. Desse modo, como os pequenos comerciantes do circuito inferior não dispõem de recursos para adquiri in loco, dependem, em grande parte, da ação dos intermediários e sua grande capacidade de armazenamento, já que os estoques do circuito inferior são pequenos.

Nessa categoria de intermediários, encontram-se também os donos de caminhão, que podem servir como meros transportadores a serviço de atacadistas ou como comerciantes. Os elementos essenciais para o funcionamento do circuito inferior são o crédito, os intermediários financeiros e o dinheiro líquido.

O crédito é necessário para os agentes e consumidores, já que para os primeiros é a única forma de se iniciar ou se manter em atividade, enquanto para o segundo grupo é a possibilidade de acesso ao consumo. Os intermediários fornecem crédito aos agentes, frequentemente em mercadorias, mas também em dinheiro e estabelecendo a ligação entre produtores e vendedores. Destacam-se os atacadistas, que fazem a ligação com o circuito superior (ibidem).

Dessa maneira, pode-se verificar claramente a forma como o impacto da forma como o território rege o dinheiro (SANTOS, 1999), isto é, como o fluxo monetário é impactado pelo território, já que as características de cada um dos circuitos em relação ao dinheiro demonstra claramente como o circuito superior é impactado pelos recursos financeiros que vem de fora, enquanto o circuito inferior é menos impactado por tais fluxos.

O dinheiro líquido representa o pagamento em numerário, fundamental para os clientes, mas também para os agentes, pois permite a quitação, ainda que parcial de suas dívidas, permitindo a obtenção de novo crédito. Os atacadistas dele dependem para pagar seus compromissos bancários ou para adquirir os bens dos produtores.

Dada à importância do crédito, a importância do endividamento é ressaltada, tornandose a usura, prática frequente. Essa importância do crédito também ocorre devido ao imenso desequilíbrio entre a massa monetária à disposição do circuito inferior e a massa de usuários, pois o recurso ao crédito torna-se indispensável e a aceleração da circulação fiduciária torna-se um corolário da carência de liquidez. 
Há, no circuito inferior, verdadeira fome de dinheiro líquido. A insuficiência de capital exige que se recorra ao crédito para a entrada ou manutenção de uma atividade produtiva. Contudo, para a manutenção do crédito é necessário dinheiro líquido para efetuar, ao menos em parte, o pagamento das dívidas contraídas. O dinheiro é o primeiro pagamento para se obter o crédito e posteriormente como prestação para conservá-lo, atuando como um "lubrificante" nas engrenagens do circuito inferior. Constata-se mais uma vez a relação entre território e dinheiro (SANTOS, 1999).

Para obter um lucro maior, é então necessário livrar-se do intermediário através do dinheiro líquido. Por isso, comerciantes do circuito inferior utilizam-se de soluções engenhosas como a venda com prejuízo, o comércio triangular, além das associações de ajuda mútua e das associações financeiras.

Os atacadistas fazem a ligação entre o circuito inferior e o superior, pois são os únicos com acesso ao crédito bancário. Esses intermediários fornecem a mercadoria e o crédito necessário, em condições particulares, caracterizados por operações pequenas e de curto prazo. Para evitar a inadimplência, os atacadistas limitam suas atividades a clientelas conhecidas. O reembolso do empréstimo raramente é integral.

Para o consumidor pobre o crédito é fundamental. Contudo, como não atende as exigências de crédito do circuito moderno. Somente o pequeno comércio do circuito inferior está adaptado as suas condições de venda a crédito e de fracionamento da mercadoria, sendo que a necessidade de crédito é, ainda, aumentada pela modernização do consumo. Assim, ocorre um aumento do endividamento generalizado para a manutenção do consumo, ressaltando-se que neste circuito as necessidades de consumo originam o crédito, podendo gerar, inclusive, práticas usurárias.

Outra característica importante do circuito estudado é a alta margem de lucro, devido à elevação do preço, decorrente do fracionamento da mercadoria, embora o lucro global seja pequeno. Esse processo acaba castigando o cliente mais pobre.

Contudo, existe, ainda, no circuito inferior um mecanismo que pode abaixar os preços, através da negociação direta cliente vendedor (pechinchar), já que pode ser conveniente vender ainda com certo prejuízo para esvaziar o estoque e obter dinheiro líquido. Enquanto o circuito superior cria a conjuntura, o inferior se adapta às condições estruturais para funcionar. Possui como característica intrínseca grande flexibilidade, favorecido como é pela divisibilidade e mobilidade de sua mão de obra e do seu capital. 
Um grande impacto da modernização é o consumo crescente de produtos modernos pela população pobre, que fez crescer novas atividades no circuito inferior, como as oficinas mecânicas.

O circuito inferior é dotado de plena racionalidade. Apresentando-se como um sistema funcional. Possui complementariedade e concorrência em relação ao circuito superior e viceversa, não sendo, pois, estanques. Há consumidores que compram em ambos os circuitos, além de que as atividades de um circuito demandam inputs do outro, de modo que haja um equilíbrio estável entre os dois sistemas. Contudo, a evolução e o comportamento dos dois sistemas estão ligados a variáveis que podem ser comuns ou não (SANTOS, 2006).

Uma variável específica do circuito inferior é a sua base fundamental na força de trabalho, além da dispersão da população e o caráter sazonal.

Como variável comum aos dois circuitos podemos destacar a estrutura do aparelho de produção e comercialização presente em uma cidade, além da distribuição de renda, possibilidades de crédito, grau de abertura da população ao consumo moderno, da importância do emprego governamental e das migrações regionais, tipo e ritmo das atividades da região, além da estrutura e organização dos transportes na cidade.

Também influem os dados culturais, a intervenção do crédito, relevantes para o entendimento dos mecanismos dos circuitos comerciais. É importante relembrar que nenhuma variável age isoladamente, antes, participa de um feixe de ações, inserindo-se, ainda, nas condições de tempo e espaço correspondentes.

\section{O IMPACTO DA MODERNIZAÇÃO NOS CIRCUITOS DA ECONOMIA URBANA: O CASO DA FEIRA DOS IMPORTADOS EM BRASÍLIA}

$\mathrm{O}$ impacto que a modernização recente gerou no funcionamento dos circuitos da Economia Urbana pode ser refletido nas práticas econômicas dos setores inferiores da economia urbana, a exemplo do objeto de análise deste trabalho: a feira dos importados de Brasília.

Buscou-se verificar, tendo como ponto de partida as características do Circuito Inferior da Economia Urbana já apresentadas no item anterior, quais inovações as novas variáveis determinantes da divisão territorial, quais sejam, a tecnociência, a informação e as finanças (SILVEIRA, 2009) impõem ao funcionamento do mencionado segmento da economia das cidades do mundo subdesenvolvido. 
A tecnociência, como apresentado por Silveira (2009), age como verdadeira ponte, permitindo a ligação entre as outras variáveis, contribuindo para a formação de uma grande unicidade. Assim, o imenso fluxo de informações, aliado a crescente financeirização da economia urbana, mesmo no Circuito Inferior, graças às recentes inovações técnicas, provocaram mudanças em seu funcionamento.

Interessante, ainda apontar para o efeito do desenvolvimento de áreas de especialização. Essas são um fenômeno metropolitano, onde o trabalho se especializa e divide em um mesmo circuito de produção (SILVEIRA, 2004).

Ademais, deve-se considerar a importância do consumo para a organização divisão territorial do trabalho, questão muito relevante, como percebido por Silveira (2015, p. 249):

Mas essa modernização que reorganiza os fatores de produção e provoca novos processos e manifestações urbanas não se completaria sem o consumo que, na atualidade, ganha contornos antes nunca vistos, com uma extraordinária difusão social e territorial, provocada não apenas pela ação das grandes empresas, mas também do Estado.

A complexidade da realidade dos circuitos da economia urbana inferior ficou acentuada quando da realização de pesquisa de campo na Feira dos Importados de Brasília. Tendo como universo o número total de permissionários, e buscando-se uma margem de erro de $10 \%$, com um nível de confiança de $80 \%$, mantendo-se a heterogeneidade da amostra em 10\%, trabalhouse com um total de 11 (onze) entrevistados, sendo 7 (sete) permissionários de boxes, 3 (três) de quiosques e 1 (um) proprietário de boxes alugados a terceiros.

Vale salientar que quiosques são lojas que possuem áreas maiores e ocupam a área mais externa da Feira, correspondente aos lados do quadrilátero que a forma. Já os boxes ocupam todo o interior da feira, possuindo áreas de metragem inferior aos quiosques. A partir da realidade analisada, verificou-se a atividade desenvolvida pela organização entrevistada, e buscou-se as principais características do Circuito Inferior da Economia Urbana, verificando a situação da força de trabalho empregada, o nível de burocratização apresentado pelas lojas e o impacto das já mencionadas variáveis dominantes, isto é, a tecnociência, a informação e as finanças na organização do espaço em tela.

Em cada um dos aspectos pesquisados, buscou-se verificar se ainda há, de fato, correspondência entre o proposto por Milton Santos (1979) e a realidade atual.

O Circuito Inferior, como apresentado por Santos, tem como uma de suas características principais ser intensivo em mão de obra. Apesar de empregar um número pequeno de 
funcionários por estabelecimento, emprega um contingente elevado de mão de obra total, já que há uma grande pulverização de estabelecimentos. Tal fato fica destacado nos dados da pesquisa de campo. O número máximo de funcionários apresentados por boxes foi de 3 (três) funcionários, sendo que dos 7 (sete) boxes entrevistados apenas um atingiu este valor. Já nos quiosques esse número é maior tendo atingido 8 (oito) funcionários. Porém, incluem-se nesse valor os dois filhos do proprietário, sua esposa e o próprio. Nos outros quiosques entrevistados o número manteve-se semelhante aos dos boxes, sem se afastar do número de três contratados.

Desse modo, e tendo em vista que o número médio de funcionários por estabelecimento é de três (3), estima-se que a força de trabalho empregada na Feira dos Importados seja de aproximadamente 5.274 (cinco mil, duzentas e setenta e quatro) pessoas para um total de 1.758 estabelecimentos.

Outra característica relevante apontada por Santos é a utilização de mão de obra familiar. Mais uma vez a formulação de Milton Santos se mostrou atual, pois dos entrevistados $70 \%$ utilizam-se de mão de obra familiar, com forte presença dos próprios proprietários dos estabelecimentos (seis boxes e um quiosque).

Não se identificou nos estabelecimentos entrevistados a ausência de vínculo formal de emprego como à época da formulação da teoria, ou seja, todos os funcionários, tanto dos boxes quanto dos quiosques possuíam registro em Carteira de Trabalho. Mesmo os proprietários que trabalhavam em seus estabelecimentos possuíam registro como Microempreendedor individual. Supõe-se que tal fato se deva a uma maior ação de fiscalização do Estado, pois como já proposto por Santos (1979), a ação estatal sobre o Circuito Inferior ao invés de fomentá-lo busca exercer um controle, burocratizando-o.

Outro ponto apontado por Santos e também confirmado na pesquisa foi o emprego de grande número de migrantes. De todos os entrevistados 70\% (setenta por cento) não eram originários de Brasília. Em que pese o Distrito Federal ser uma região em que o percentual de moradores oriundos de outras regiões é alto, tal percentual reforça a conclusão de que o Circuito Inferior recebe aqueles que, por se originarem de outras cidades e regiões, tem dificuldade em acessar os empregos disponíveis no Circuito Superior. Assim, 50\% (cinquenta por cento) dos entrevistados tinham como origem o estado de Goiás, o que se explica pela proximidade 
geográfica do Distrito Federal e os outros $20 \%$ (vinte por cento) dos entrevistados e que são migrantes eram originários da região Nordeste (Bahia e Maranhão).

Ainda em relação a força de trabalho, foi possível constatar uma grande presença de vendedores orientais, com aparência de chineses. Tais empregados apresentavam dificuldade de se expressar em português e foram extremamente refratários a serem entrevistados. Desse modo, em que pesem as diversas tentativas realizadas, não foi possível entrevistar nenhum desses imigrantes.

Tal fato deve-se, possivelmente, a situação irregular desses, já que há hipótese de possuírem os vistos exigidos para exercerem atividade remunerada naquelas condições é extremamente exígua. Pode-se realizar tal afirmação pois a política de vistos nacional busca atender demandas específicas e especializadas, e não trabalhos como os desenvolvidos na Feira dos Importados.

Cabe ressaltar que a forma de contratação no Circuito Inferior apresenta peculiaridades, já que todos os entrevistados empregados foram contratados através da indicação de conhecidos em comum com os empregadores, não se recorrendo à oferta de vagas em meios de comunicação como jornais e outros meios de comunicação.

Também é possível afirmar que os entrevistados moram em regiões periféricas do Distrito Federal e do seu entorno, acarretando grandes deslocamentos até o local de trabalho. Segundo o resultado da pesquisa realizada, $50 \%$ (cinquenta por cento) dos entrevistados moram em Ceilândia (25\%) e em Samambaia (25\%), duas das regiões mais carentes do Distrito Federal. Os demais entrevistados residiam em Planaltina (8\%), Vicente Pires (8\%), Gama (8\%), Taguatinga (8\%) e Vicente Pires, também áreas periféricas do Distrito Federal.

Segue mapa mostrando o posicionamento dos principais locais de moradia dos entrevistados em relação ao SIA, onde está localizada a Feira dos Importados: 
Figura 5: Mapa do Local de Residência dos Empregados na Feira dos Importados

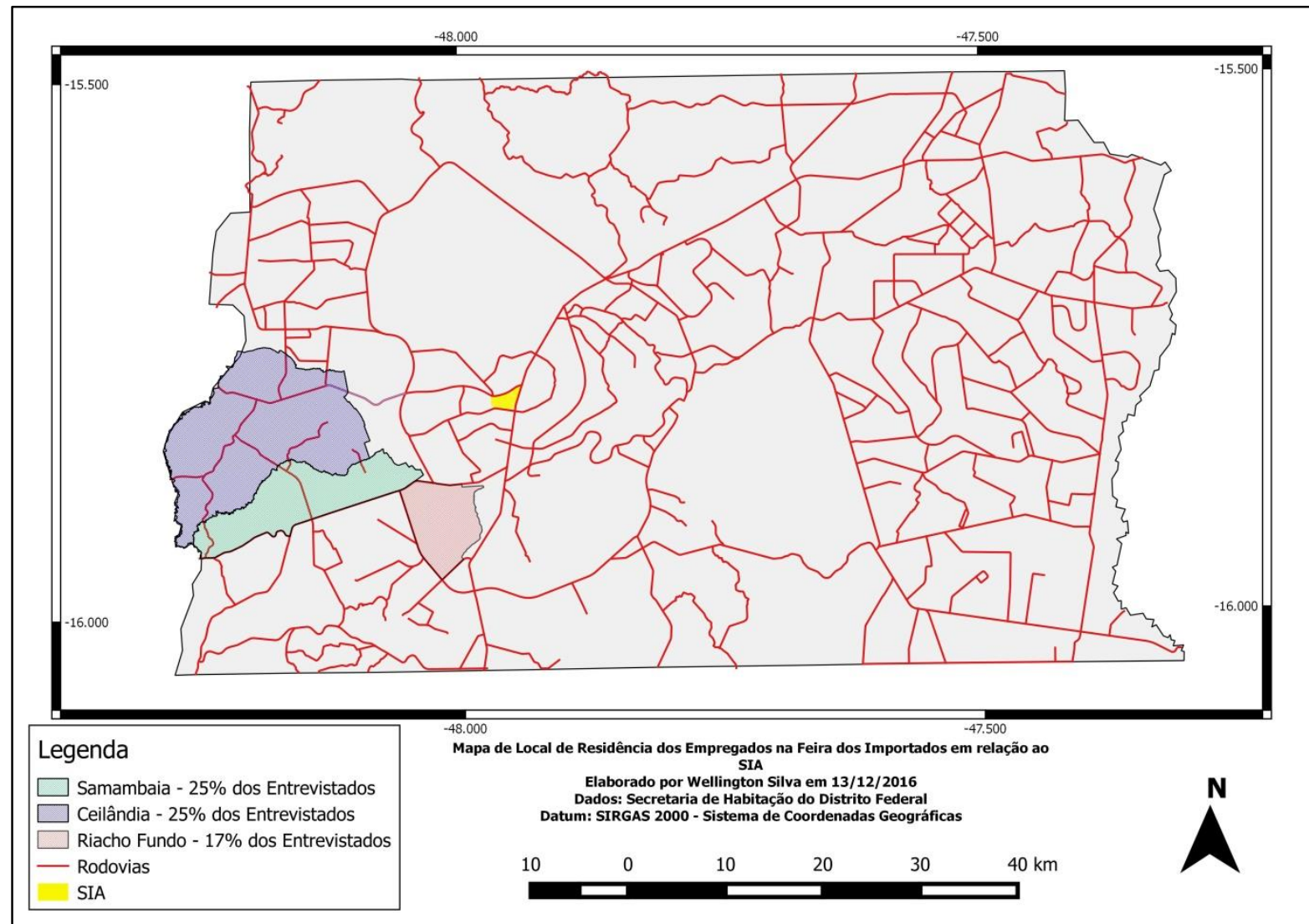

Fonte: Secretaria de Habitação do DF, 2016

Da análise do mapa acima, em um programa do tipo SIG, foi possível verificar a distância média aproximada de deslocamento necessário, tendo como base a malha rodoviária constante do mapa, para que um trabalhador morador de uma das áreas acima registradas chegasse até seu local de trabalho. Assim, o deslocamento exigido da Ceilândia até o SAI é de aproximadamente $25 \mathrm{Km}$, o de Samambaia é de $32 \mathrm{Km}$, enquanto para se chegar do Riacho Fundo até o SAI deve-se percorrer cerca de $28 \mathrm{Km}$. Desse modo, é possível verificar que a maior parcela dos empregados na Feira dos Importados se submete a grandes deslocamentos diários entre sua residência e o local de trabalho.

Houve uma grande mudança em relação ao desenvolvido à época do estabelecimento da Teoria dos Circuitos da Economia Urbana e a situação atual do nível de formalização dos estabelecimentos do Circuito Inferior em funcionamento na Feira dos Importados. Ao contrário da informalidade esperada, a totalidade dos estabelecimentos pesquisados possuíam registro 
junto aos órgãos federais e distritais de tributação e controle, além de registrarem a integralidade de seus funcionários, como já dito anteriormente.

Segundo declarado pelos entrevistados, em todas as vendas havia a emissão de nota fiscal, sendo que se verificou a utilização de máquinas da chamada nota fiscal eletrônica nestes estabelecimentos, demonstrando como uma das variáveis chaves da atualidade, isto é, a informação impacta diretamente na forma de organização do Circuito Inferior.

Tais máquinas aumentam o controle da fiscalização tributária sobre as operações, já que tornam impossível a antiga prática de emissão de nota fiscal "calçada", isto é, a emissão tão somente da via do consumidor, evitando-se o registro da venda nos documentos de posse do vendedor. Assim, devido a ação Estado em relação às atividades do Circuito Inferior, o nível de informalidade tem diminuído.

Também devido à ação estatal de repressão de ilegalidades e fiscalização, todos os entrevistados foram unânimes em informar que somente adquirem mercadoria de seus fornecedores com nota fiscal.

Mesmo em atividades em que seriam esperadas vendas de mercadorias de origem estrangeira sem a devida comprovação da origem, o que configuraria o crime de descaminho, previsto no artigo 334 do Código Penal, como material de informática e seus acessórios, todos os entrevistados apresentaram, ainda que não houvesse solicitação, notas fiscais da origem de seus produtos.

Em que pese ser impossível de confirmar a veracidade das notas fiscais apresentadas, em especial pelo fato de elas, em sua maioria, terem origem em estabelecimentos localizados na fronteira do Brasil com o Paraguai, tal providência é reflexo de uma preocupação com um certo grau de formalização. Ademais, impede-se que uma simples fiscalização de rotina, baseada tão somente na checagem de documentos, tenha consequências danosas ao estabelecimento, já que para se comprovar ou não qualquer irregularidade seria necessária uma análise mais profunda incompatível com o tipo de fiscalização normalmente realizado.

Ainda em relação ao nível de formalização e legalidade da origem da mercadoria, podese perceber a venda de vestuário contrafeito de marcas famosas. Trata-se do melhor exemplo do efeito demonstração, uma das principais explicações para o desenvolvimento do Circuito Inferior. 
Graças à Revolução do Consumo, impulsionada pela propaganda, graças a uma difusão cada vez maior da informação, graças às novidades da tecnociência, as camadas populares têm o desejo de consumir roupas de marcas famosas de alto custo, vendidas no Circuito Superior.

Como não podem adquiri-las pelo preço original, compram cópias vendidas em estabelecimentos tipicamente do Circuito Inferior, como se pôde verificar durante a pesquisa de campo. Mesmo esses estabelecimentos afirmaram possuir nota fiscal comprovando a origem da mercadoria. Dessa forma, a ação de fiscalização fica mais difícil, uma vez que seria necessário que agentes do Estado apreendessem tais mercadorias para uma análise mais detalhada do produto de forma a comprovar ou não sua origem falsificada, não sendo possível comprovar de plano a falsidade.

E, ainda que se comprove a falsidade, ao menos no campo do Direito Penal, não haveria ação imediata possível, já que esses crimes são considerados pela legislação brasileira como crimes de ação penal privada, ou seja, crimes em que a polícia somente pode agir somente se houver uma provocação da vítima. Dessa forma, seria necessária uma representação formal do titular da marca para que houvesse uma ação policial. Desse modo, verifica-se que há toda uma preocupação em uma formalização das atividades do Circuito Inferior, ao menos na Feira dos Importados, decorrente das inúmeras ações de repressão executadas pelo Estado naquele local ao longo do tempo, conforme demonstram as matérias jornalísticas ${ }^{34}$.

Outro ponto que reforça a formalização é a existência de uma associação formalmente constituída responsável pela administração da Feira, recolhendo os valores devido a título de água e luz de cada um dos proprietários, e repassando às concessionárias, além de estabelecer as regras de convivência, funcionando de modo similar a um condomínio. Há inclusive eleição para os cargos de direção, votando os proprietários.

\footnotetext{
${ }^{3}$ Informação on-line, conferir em: http://www.correiobraziliense.com.br/app/noticia/cidades/2015/03/17/interna cidadesdf,475802/comerciantesfecham-pista-no-sia-apos-operacao-na-feira-dos-importados.shtml

${ }^{4}$ Informação on-line, conferir em: http://g1.globo.com/distrito-federal/videos/v/receita-federal-faz-operacao-nafeira-dos-importados/3732396/
} 


\section{Tecnociência e Informação}

Como variáveis determinantes da divisão de trabalho no período atual, a tecnociência e a informação impactam diretamente no funcionamento do Circuito Inferior na Feira dos Importados.

A própria existência da feira é devida à tecnociência, já que conforme mencionado anteriormente, embora haja uma vasta gama de produtos e serviços ali disponíveis, variando desde a venda de tapetes até lentes para óculos, grande parte dos estabelecimentos ocupa-se da venda de materiais de informática, seus acessórios e serviços a eles relacionados, como reparos e atualizações. Assim, de todos os produtos e serviços possíveis, dedicam-se a vender produtos relacionados a tecnociência cerca de $44 \%$ (quarenta e quatro por cento) dos estabelecimentos ali existentes, um predomínio absoluto em relação às demais mercadorias e serviços.

Isso se deve muito em razão do efeito demonstração, uma vez que gera na camada mais pobre uma necessidade de consumo de tais bens relacionados a técnica e à informação, de uma forma nunca antes vista.

Assim, para atender essa nova demanda, há uma forte necessidade de crédito, como se verá a seguir, bem como ocorre um simultâneo aumento da oferta de bens e serviços ligados à tecnociência a preços mais adequados às camadas menos favorecidas. Tal tarefa é realizada pelo Circuito Inferior da Economia Urbana, e, no Distrito Federal, notadamente pela Feira dos Importados.

A tecnociência e a informação também influem na maior necessidade de formalização dessas atividades do Circuito Inferior, já que aumentam as possibilidades de exercício do poder controlador do Estado, através de ferramentas como a nota fiscal eletrônica e o registro eletrônico de funcionários.

Verifica-se, assim, que tais variáveis são uma das responsáveis diretas pela própria existência da Feira dos Importados em seu modelo atual.

\section{Financeirização}

Outra variável determinante da atual distribuição espacial é a financeirização das atividades econômicas. Em relação ao momento da proposição da Teoria dos Circuitos da economia Urbana por Milton Santos, em 1975, talvez seja nesse campo que tenham ocorrido as maiores mudanças. 
Como observou Silveira (2009), cada vez mais os grandes bancos têm ocupado espaço junto a áreas degradadas, porém de grande circulação de pessoas, de modo a fornecer serviços financeiros às demandas banais da camada pobre da população.

As grandes financeiras e os grandes bancos passam a oferecer crédito facilitado à parcela significativa da população urbana que, em momentos anteriores, era alijada de tal processo. No entanto, devido à revolução do consumo, e seu efeito demonstração, houve uma atração dos grandes bancos e financeiras pelas camadas sociais inferiores da população, já que esta queria consumir e para tanto necessitava de crédito.

Segundo Dias e Lenzi (2009, p.115):

[...] o núcleo de inovações tecnológicas de base microeletrônica engendra mudanças nas formas assumidas pelo dinheiro e pelas finanças. Dinheiro virtual, cartões magnéticos inteligentes e transferência eletrônica de fundos rematerializam o dinheiro, que se transforma em unidades de informação transmitidas pelas redes de telecomunicações.

No entanto, tal crédito caracteriza-se por ser extremamente caro, baseado principalmente em cartões de crédito ou empréstimos pessoais ditos descomplicados, porém com spreads altíssimos.

Essa situação, constatada por Silveira (2009) aparece claramente nos resultados das enquetes realizadas na Feira dos Importados de Brasília.

A totalidade dos estabelecimentos entrevistados aceita cartão de crédito. E não poderia ser diferente. Como já se disse, a necessidade de crédito é imperiosa para atender as demandas do consumo geradas pelo já mencionado efeito demonstração.

Assim, tendo em vista que grande parte de suas vendas se dão por intermédio do cartão de crédito, hoje portado inclusive pelas camadas populares, os estabelecimentos do circuito inferior se veem obrigados a aceitar um nível de financeirização superior ao anteriormente estabelecido.

Desaparecem figuras como os agiotas, substituídos pelo crédito fácil e extremamente caro disponível pelo sistema financeiro. Não se vende mais fiado, isto é, aquele crédito sem juros oferecido pelo comerciante com base na confiança mútua.

Cada vez mais dependente do crédito para efetuar suas vendas, mesmo de pequena monta, os estabelecimentos do Circuito Inferior cada vez mais passam a depender do crédito 
para pagar seus fornecedores e honrar seus compromissos, o agente do Circuito Inferior é obrigado a recorrer às instituições financeiras para seu capital de giro, aumentando desse modo a dependência do Circuito Inferior em relação ao Circuito Superior (SILVEIRA, 2009).

Uma consequência desse aumento da participação do crédito formal no Circuito Inferior é o aumento do prazo de reposição das mercadorias. Ao contrário do que identificou Milton Santos, durante a pesquisa de campo, verificou-se que a reposição dos estoques variava entre sete e vinte dias. Ou seja, desaparece a necessidade de reposição quase diária dos produtos, havendo, assim, o aparecimento de um estoque de mercadorias, ainda que de pequeno volume.

Em nenhum dos entrevistados identificou-se recebimento de mercadorias em prazo inferior a uma semana.

\section{Outros Achados da Pesquisa de Campo}

Outro ponto a ser observado diz respeito a propriedade dos imóveis (boxes ou quiosques) onde funcionam as lojas. A maioria absoluta dos entrevistados não era o proprietário do espaço onde funcionava a loja. Somente em dois quiosques, o proprietário do espaço era o mesmo do estabelecimento comercial. Em relação aos boxes, essa coincidência não ocorreu uma única vez.

Assim, entre os custos fixos envolvidos no funcionamento dos estabelecimentos há o aluguel, cujo valor varia entre $\mathrm{R} \$ 900,00$ e $\mathrm{R} \$ 1.400,00$ por boxe dependendo da localização, sendo mais caros aqueles que se encontram próximos aos corredores centrais, por possuírem uma maior circulação de pessoas.

Como impacto da atual crise econômica, os valores dos aluguéis apresentaram forte queda nos últimos dois anos de cerca de $30 \%$ (trinta por cento).

É importante ressaltar como se dá aquisição do espaço no interior da Feira dos Importados. Como já mencionado, a área onde ela está localizada era originariamente pública. Assim, a aquisição do espaço se dá através da estatal que administra a propriedade das terras públicas no Distrito Federal, denominada TERRACAP.

Tal organização é responsável pelo controle e alienação das terras públicas do Distrito Federal. Assim, a aquisição do espaço na Feira dos Importados é feita junto à TERRACAP, onde se pode contar com financiamento em até dez anos. Contudo, atualmente, a forma de aquisição mais comum é a transmissão entre proprietários, já que inexistem espaços 
disponíveis. O valor alcançado, após a forte desvalorização já mencionada, é de cerca de R\$ $100.000,00$ por um boxe.

Outro ponto identificado foi a existência de uma solidariedade entre os diversos estabelecimentos, como já apontado por Milton Santos. Todos os entrevistados informaram que, em caso de indisponibilidade da mercadoria desejada, indicariam outra loja onde o produto pudesse ser encontrado.

Comprovou-se, ainda, através da pesquisa a existência de uma complementariedade entre os circuitos superior e inferior, que vai além da já exposta quando da análise da questão da financeirização.

Parcela considerável das lojas entrevistadas (20\%), a totalidade quando analisamos aquelas destinadas à venda de produtos de informática e eletroeletrônicos, possui como produto mais vendido bem fabricado por uma das grandes marcas internacionais, destacando-se celulares Samsung e o aparelho Chromecast da Google.

Assim, tanto pode-se afirmar que existe uma relação de competição entre lojas localizadas na Feira dos Importados e suas correspondentes localizadas em Centros Comerciais destinados a um público de maior renda, já que se pode encontrar em ambos os lugares os mesmos produtos, como também que a dependência do circuito inferior em relação ao circuito superior está presente fortemente também pelo fornecimento de produtos, em especial os de maior tecnologia, principais produtos vendidos na área estudada, como já dito.

Isto ocorre, principalmente, porque o desenvolvimento e produção deste tipo de bem exige um grande investimento em pesquisa, ciência e tecnologia, estando, pois, fortemente ligados às formas de produção do Circuito Superior da Economia Urbana.

\section{ALGUMAS CONCLUSÕES}

Os resultados deste artigo apontam para situações concretaras de materialização das características do Circuito Inferior da Economia Urbana, como traçadas originalmente por Milton Santos.

Diante deste cenário, verificou-se se o impacto das variáveis chaves do período, isto é, a tecnociência, a informação e as finanças, como haveria evoluído o funcionamento do Circuito 
Inferior, tendo como base o resultado de uma pesquisa de campo executada na Feira dos Importados do Distrito Federal.

Focou-se, além das variáveis acima citadas, também no nível de formalização dos estabelecimentos, na origem de suas mercadorias e também nas mudanças relacionadas à força de trabalho. Verificou-se, embora tenha havido consideráveis impactos, em especial no tocante à financeirização das atividades do Circuito Inferior e na formalização de seus estabelecimentos, graças ao impacto da tecnociência, que as características chaves do Circuito Inferior permanecem válidas.

Continua existindo um circuito da economia urbana criado pela revolução do consumo, destinado a atender às camadas mais populares cujos postos de trabalho são ocupados pelos excluídos do Circuito Superior e baseado em intensivo emprego de mão de obra. Desse modo, permanecem válidas as premissas desenvolvidas por Milton Santos na década de 1970.

Todavia, o impacto da tecnociência, da informação e da financeirização sobre os agentes e atividades do Circuito Inferior muitas vezes se apresenta de forma perversa. $\mathrm{O}$ fácil acesso ao crédito caro, fornecido pelas financeiras, cria um efeito de abismo social, criando condições de endividamento que submetem a população pobre a uma situação perversa de perpetuação da pobreza. O Estado, por sua vez, utiliza-se dos mecanismos propiciados pela informação e pela técnica, age como repressor em vez de buscar mecanismos de diminuição dos impactos negativos de tal situação.

Em suma, somente no resultado de pesquisas que apontem para o quadro acima descrito é possível traçar políticas públicas que combatam tal efeito perverso, pois é necessário o conhecimento territorial da economia para a ação. Desse modo, ressalta-se a importância e a atualidade da discussão a respeito dos dois Circuitos da Economia Urbana e seus múltiplos entrelaçamentos com os fenômenos territoriais resultantes da mediação das relações entre os sujeitos e o meio. 


\section{REFERÊNCIAS BIBLIOGRÁFICAS}

DIAS, Leila Christina, LENZI, Maria Helena. Reorganização espacial de redes bancárias no Brasil: processos adaptativos e inovadores. Cadernos CRH, v. 22, n. 55, p. 97-117, 2009.

Feira dos Importados. Disponível em http://www.feiradosimportados.net.br/historico. Acesso em 17/11/2016.

LINHARES, Lucas. Os Dois Circuitos da Economia Urbana no Eixo Sul da Região Metropolitana de Belo Horizonte: uma análise microespacial do caso do barirro Jardim Canadá. In: Encontro Nacional da ANPUR, X, 2003, Belo Horizonte. Anais de Resumo. Belo Horizonte: 2003, p. 1-15.

SANTOS, Milton. O Espaço Dividido: Os dois circuitos da economia urbana no países subdesenvolvidos. São Paulo: Livraria Francisco Alves Editora S.A., 1979. O Dinheiro e o Território. In: Conferência de Inauguração do

Mestrado em Geografia na Universidade Federal Fluminense, 1999, Niterói.

. A Natureza do Espaço: Técnica e Tempo, Razão e Emoção. São Paulo: Editora da Universidade de São Paulo, 2006.

SILVEIRA, Maria Laura. Finanças, Consumo e Circuitos Da Economia Urbana. Caderno CRH, Salvador, v. 22, n. 55, p. 65-76, 2009.

. Globalización y Circuitos de la economía Urbana en Cuidades Brasileñas.

Cuadernos del CENDES, v. 3, n. 57, p. 1-21, 2004.

. Modernização contemporânea e nova constituição dos circuitos da economia urbana. Geousp - Espaço e Tempo (Online), v. 19, n. 2, p. 246-262, 2015.

Recebido em Junho de 2019

Aprovado em Agosto de 2019

Publicado em Agosto de 2019 